\title{
Interferência de Plantas Daninhas na Cultura de Algodão em Sistema de Plantio Direto ${ }^{1}$
}

\author{
Weed Interference in Cotton Crop Under No-Tillage System
}

\author{
FREITAS, R.S. ${ }^{2}$, BERGER, P.G. ${ }^{3}$, FERREIRA, L.R. ${ }^{3}$, CARDOSO, A.A. ${ }^{3}$, FREITAS, T.A.S. ${ }^{4}$ e \\ PEREIRA, C.J. ${ }^{5}$
}

\begin{abstract}
RESUMO - Em experimento conduzido em solo de textura argilosa, localizado no município de Viçosa-MG, durante o ano agrícola 1998/1999, avaliaram-se os períodos de convivência de plantas daninhas com a cultura do algodão conduzida em sistema de plantio direto. Foram avaliados os tratamentos: períodos de 0, 15, 30, 45, 60 e 75 dias após a semeadura da cultura do algodão em convivência com as plantas daninhas; depois desse período a cultura foi mantida livre da competição com as plantas daninhas até a colheita, em delineamento de blocos ao acaso, com quatro repetições. As parcelas foram constituídas de seis fileiras com $4 \mathrm{~m}$ de comprimento, espaçadas de $0,9 \mathrm{~m}$, com seis plantas por metro. As plantas daninhas foram avaliadas ao final de cada período de convivência, determinando-se o número e a biomassa seca da parte aérea de cada espécie. Também foram avaliadas na cultura a altura média das plantas, aos 125 dias após a emergência (DAE), o número de maçãs por planta, o número de nós até a inserção do primeiro ramo frutífero e, na colheita, a produtividade de algodão em caroço. O acúmulo médio de biomassa seca do total de plantas daninhas foi de $4,7 \mathrm{~g} \mathrm{~m}^{-2}$ dia $^{-1}$. Comparando os tratamentos com e sem interferência, verificou-se que a presença das plantas daninhas durante todo o ciclo da cultura aumentou o número de nós até a inserção do primeiro ramo frutífero e reduziu o número de maçãs e a altura das plantas, além de reduzir a produtividade de algodão em caroço em $81,2 \%$. O período que antecede a interferência das plantas daninhas (PAI), considerando uma perda tolerável de 5\% na produtividade de algodão em caroço, foi de $14 \mathrm{DAE}$.
\end{abstract}

Palavras-chave: Gossypium hirsutum, palha de sorgo, competição, produtividade, sistema de plantio direto.

\begin{abstract}
An experiment was conducted in clay soil texture, in Viçosa-MG, Brazil, during the growing season 1989/1999, to evaluate the periods of weed coexistence in a cotton crop under no-tillage. The treatments were: $0,15,30,45,60$ and 75 days after crop seeding under weed coexistence, and maintained weed free until crop harvest. The plots consisted of six rows $4 \mathrm{~m}$ long, and $0.9 \mathrm{~m}$ spaced, with six plants per meter. At the end of each coexistence period, the weeds were evaluated, by determining the number of species and shoot dry matter weight. The average crop plant height was also evaluated; 125 days after emergence (DAE), boll numbers per plant, and node numbers until insertion of the first fruitful branch were also evaluated, while cotton productivity was evaluated at harvesting. The average accumulation of the total dry matter of weeds was $4.7 \mathrm{~g} \mathrm{~m}^{-2}$ day $^{-1}$. When comparing the treatments with and without weed interference, it was observed that weed interference throughout the cycle increased the average node numbers until insertion of the first fruitful branch, but reduced the average boll numbers and height of the plants. Weed interference throughout the cotton plant cycle caused a reduction of $81.2 \%$ in cotton productivity. Considering the $5 \%$ loss in productivity as acceptable, the period previous to weed interference was 14 DAE.
\end{abstract}

Key words: weed, sorghum straw, competition, productivity, no-till.

1 Recebido para publicação em 30/1/2002 e na forma revisada em 7/8/2002.

Parte da tese de Mestrado em Fitotecnia apresentada à Universidade Federal de Viçosa - UFV, 36570-000 Viçosa-MG.

2 Doutorando, Dep. de Fitotecnia da UFV, <rogsoares@ hotmail.com>3 Professores do Departamento de Fitotecnia da UFV; ${ }^{4}$ Mestrando do Departamento de Produção Vegetal da Universidade Estadual Norte Fluminense - UENF - RJ; ${ }^{5}$ Estudante de graduação da UFV. 


\section{INTRODUÇÃO}

O manejo correto de plantas daninhas é fundamental para o sucesso na produção de algodão, tanto no sistema convencional como no de plantio direto. Guando não manejadas de modo adequado, essas plantas podem causar redução na produtividade, e algumas delas podem prejudicar a qualidade do produto colhido, aumentando custos e reduzindo o valor da fibra (Righi et al., 1965).

O grau de interferência na associação planta daninha-cultura depende de fatores ligados tanto à comunidade infestante (composição específica, densidade e distribuição) como à própria cultura (gênero, espécie ou cultivar, espaçamentos entre linhas e densidade de semeadura). Depende ainda da época e duração do período de convivência planta daninhacultura e das condições edáficas e climáticas (Blanco, 1972; Pitelli, 1985).

Diversos trabalhos, em sistema de plantio convencional, desenvolvidos em várias regiões por Blanco \& Oliveira (1976), Cia et al. (1978), Beltrão et al. (1979) e Guerra Filho (1980) mostram redução de 82 a $98 \%$ no rendimento do algodoeiro quando em convivência com as plantas daninhas durante todo o ciclo. Segundo Beltrão et al. (1979), quando o algodoeiro conviveu com plantas daninhas por todo o ciclo ocorreu redução em sua produtividade superior a 90\%. Resultados semelhantes foram observados no Estado de Minas Gerais por Laca-Buendia et al. (1979), no Norte de Minas e Triângulo Mineiro, e por Guerra Filho (1980), na cidade de Capinópolis. Nesta cidade foi observada redução de 89\% na produção de capulhos quando a cultura foi submetida à convivência com as plantas daninhas durante todo o ciclo. No Norte de Minas, a redução foi de $92 \%$, e na região Central e no Triângulo Mineiro, de 90\%. Todavia, segundo Cia et al. (1978) e Laca-Buendia et al. (1979), a convivência plantas daninhasalgodão nas primeiras semanas não causou qualquer efeito negativo nesta cultura.

Almeida (1985), comparando três sistemas de preparo de solo - preparo reduzido (uma escarificação e duas gradagens), preparo convencional (uma aração e duas gradagens) e o preparo nulo quanto à infestação por plantas daninhas -, concluiu que a movimentação do solo, representado pelo preparo convencional e reduzido, favorecia o desenvolvimento da infestação, tendo-a aumentado, em relação ao preparo nulo, em 187 e $213 \%$, respectivamente. Também Schultz (1987), estudando o efeito do tipo de preparo do solo sobre a quantidade de plantas emergidas, verificou que na área com uma aração emergiram 103 plantas $\mathrm{m}^{-2}$; na área com aração mais gradagem ocorreu a emergência de 134 plantas $\mathrm{m}^{-2}$; na área que foi arada, gradeada e compactada ocorreu a emergência de 320 plantas $\mathrm{m}^{-2}$; e na área que não foi cultivada verificou-se emergência de 80 plantas $\mathrm{m}^{-2}$.

Almeida (1985), estudando os efeitos de diferentes coberturas mortas (tremoço, trigo, triticale, colza, nabo forrageiro, centeio e aveia) sobre a emergência de plantas daninhas, constatou que as coberturas do solo com palhada da aveia, do centeio, do nabo forrageiro e da colza foram as que mantiveram o solo limpo por mais tempo. Esse autor também observou redução de biomassa de plantas daninhas quando se aumentou a biomassa de palhada utilizada para cobertura do solo. Vidal et al. (1998) verificaram a redução da infestação de Brachiaria plantaginea e Setaria faberi com o incremento dos níveis de resíduo vegetal de trigo ou aveia ( 0 a $9 \mathrm{t} \mathrm{ha}^{-1}$ ) na superfície do solo em semeadura direta.

Este trabalho teve como objetivo determinar o período anterior à interferência (PAI) de plantas daninhas na cultura do algodão cultivado em sistema de plantio direto.

\section{MATERIAL E MÉTODOS}

O experimento foi instalado em solo argiloso, no município de Viçosa-MG, no ano agrícola 1998/1999, em área com sorgo forrageiro, o qual foi dessecado por ocasião do florescimento com ghyphosate a $2,0 \mathrm{~kg}$ do ingrediente ativo (i.a.) ha-1, sendo as plantas roçadas após o efeito do herbicida. Dois dias antes da semeadura do algodão, essa área foi novamente pulverizada com glyphosate, para controle das plantas daninhas remanescentes da primeira aplicação, principalmente de Cyperus rotundus (tiririca). O sorgo forrageiro produziu palhada com biomassa seca ao ar de aproximadamente $4.500 \mathrm{~kg} \mathrm{ha}^{-1}$.

O delineamento experimental utilizado foi o de blocos ao acaso, com sete tratamentos e 
quatro repetições. Os tratamentos foram os períodos de convivência da cultura com as plantas daninhas (Tabela 1). Cada parcela experimental foi constituída de seis fileiras de algodão com $4 \mathrm{~m}$ de comprimento, espaçadas entre si de $0,9 \mathrm{~m}$. A área útil de cada parcela foi constituída das quatro fileiras centrais, descontando-se $0,5 \mathrm{~m}$ nas extremidades como bordadura.

Tabela 1 - Períodos de convivência de plantas daninhas com a cultura do algodão. Viçosa-MG, 1998/1999

$$
\begin{aligned}
& \text { Livre das plantas daninhas até a colheita } \\
& \text { Convivência por } 15 \text { dias após a emergência (DAE) } \\
& \text { Convivência por } 30 \mathrm{DAE} \\
& \text { Convivência por } 45 \mathrm{DAE} \\
& \text { Convivência por } 60 \mathrm{DAE} \\
& \text { Convivência por } 75 \mathrm{DAE} \\
& \text { Convivência por todo o ciclo (testemunha sem capina) }
\end{aligned}
$$

Após cada período de interferência, a cultura do algodoeiro foi mantida livre de plantas daninhas até a colheita.

A semeadura do algodão foi feita mecanicamente, distribuindo-se aproximadamente 20 sementes do cultivar BRS Antares por metro de sulco, adubado previamente com $500 \mathrm{~kg} \mathrm{ha}^{-1}$ de fertilizantes da formulação 4-14-8. Aos 35 dias após a emergência do algodão fez-se o desbaste, deixando-se seis plantas por metro de linha. Foram também realizadas duas adubações em cobertura com nitrogênio aos 40 e 60 dias após o plantio, ambas com $75 \mathrm{~kg} \mathrm{ha}^{-1}$ de sulfato de amônio.

Antes de cada época de capina e no final do ciclo do algodão, nas parcelas em que as plantas daninhas e o algodoeiro conviveram por todo o ciclo, foram feitas amostragens das plantas daninhas, as quais foram separadas por espécies, contadas e pesadas. Para determinação da biomassa seca das plantas daninhas, estas, após coletadas, foram secadas a $72{ }^{\circ} \mathrm{C}$ em estufa de circulação forçada até peso constante. Cada coleta de plantas daninhas foi realizada em três pontos $\left(0,25 \mathrm{~m}^{2}\right)$, ao acaso, por parcela. Após cada período de convivência, as parcelas foram mantidas "no limpo" até a colheita.

A resposta do algodoeiro à interferência das plantas daninhas foi avaliada tomando-se como base as seguintes características da cultura: altura de planta, número médio de maçãs e produtividade de algodão em caroço. Na determinação da altura foram avaliadas 10 plantas por parcela, medindo-se a distância entre o colo da planta e seu ápice por ocasião da maturação dos capulhos. A contagem do número de maçãs foi feita aos 125 dias após a emergência da cultura, em seis plantas por parcela. Para avaliação da produtividade de algodão em caroço, consideraram-se todas as plantas da área útil de cada parcela, sendo a primeira colheita realizada quando 50\% dos capulhos estavam abertos. Em todos os tratamentos foram feitas duas colheitas.

Os resultados obtidos foram submetidos às análises de variância e de regressão. Para determinação do período anterior à interferência (PAI) das plantas daninhas no algodoeiro, admitiu-se redução de 5\% na produtividade de algodão em caroço, conforme metodologia proposta por Cousens (1988) e adaptada por Melo et al. (2001).

Na análise de regressão foi considerado o modelo polinomial $\mathrm{Y}=\mathrm{a}+\mathrm{bx}+\mathrm{b}_{1} \mathrm{x}^{2}+\mathrm{b}_{2} \mathrm{x}^{3}$, avaliando a significância dos efeitos linear, quadrático, cúbico e desvio e a raiz quadrada do modelo polinomial, ou seja, $\mathrm{Y}=\mathrm{a}+\mathrm{bx}^{0,5}+$ $b_{1} x+b_{2} x^{1,5}$, assim como, a seguir, a significância da raiz quadrada dos efeitos linear, quadrático, cúbico e desvio. Foi escolhido o modelo de efeito significativo pelo teste $\mathrm{F}$ a $5 \%$ de probabilidade, de maior $\mathrm{R}^{2}$ e de significado biológico. A testemunha (convivência planta daninha-cultura por todo o ciclo) foi comparada com os demais tratamentos pelo teste de Dunnett a $5 \%$ de probabilidade.

\section{RESULTADOS E DISCUSSÃO}

Verificou-se alta infestação de Cyperus rotundus nas primeiras avaliações $(38,4 \%$ da biomassa seca total), e a partir de 60 dias após a emergência da cultura esta espécie foi dominada por Digitaria horizontalis, Brachiaria plantaginea, Ageratum conyzoides, Raphanus raphanistrum e outras (Tabela 3). O sombreamento promovido pelas plantas de algodão, 
bloqueando a passagem de luz fotossinteticamente ativa, provavelmente constituiu o fator para redução da importância da $C$. rotundus nos períodos de avaliação posteriores, pelo fato de ser ela pouco competitiva nessas condições. Aos 75 dias após a emergência da cultura, a produção de biomassa seca das plantas daninhas foi de $307 \mathrm{~g} \mathrm{~m}^{-2}$, e no fim do ciclo a biomassa seca total gerada pelas plantas daninhas foi de aproximadamente $487 \mathrm{~g} \mathrm{~m}^{-2}$ (Tabela 3).

O acúmulo médio de biomassa seca de plantas daninhas nos períodos avaliados foi de $4,7 \mathrm{~g} \mathrm{~m}^{-2} \mathrm{dia}^{-1}$ (Figura 1). Esse fato pode ser atribuído à alta densidade de plantas daninhas (Tabela 2) e ao lento crescimento inicial do algodão. Considerando o total de plantas daninhas na área (tratamento sem capina), no final do ciclo da cultura, as principais plantas daninhas foram $D$. horizontalis, $A$. conyzoides e $B$. plantaginea. Estas espécies representaram aproximadamente $71 \%$ da biomassa total de plantas daninhas na área (Tabela 3).

A interferência de plantas daninhas afetou todas as características do algodoeiro avaliadas. Verificou-se efeito linear do período de convivência de plantas daninhas sobre a altura do algodoeiro, ou seja, redução na altura do algodoeiro com acréscimo no período de convivência. $O$ tratamento mantido livre de plantas daninhas permitiu maior crescimento, em altura, do algodoeiro (Figura 2), maior produção de maçãs e redução no número de nós para inserção do primeiro ramo frutífero (Figura 3), bem como maior produtividade de algodão em caroço (Figura 4).

Tabela 2 - Número de plantas daninhas por $\mathrm{m}^{2}$ (NP) e porcentagem de ocorrência em relação ao total de plantas daninhas nos diferentes períodos de convivência com o algodoeiro em sistema de plantio direto

\begin{tabular}{|c|c|c|c|c|c|c|c|c|c|c|}
\hline \multirow{3}{*}{ Espécie } & \multicolumn{10}{|c|}{ Período de avaliação / Dia após a emergência } \\
\hline & \multicolumn{2}{|c|}{15} & \multicolumn{2}{|c|}{30} & \multicolumn{2}{|c|}{45} & \multicolumn{2}{|c|}{60} & \multicolumn{2}{|c|}{75} \\
\hline & NP & $\%$ & NP & $\%$ & NP & $\%$ & NP & $\%$ & NP & $\%$ \\
\hline C. rotundus & 30 & 16,7 & 121 & 46,9 & 120 & 27,5 & 105 & 40,5 & 66 & 18,6 \\
\hline A. conyzoides & 39 & 22,3 & 60 & 23,2 & 202 & 47,3 & 81 & 31,2 & 205 & 57,9 \\
\hline D. horizontalis & 2 & 1,1 & 4 & 1,5 & 6 & 1,4 & 2 & 0,8 & 14 & 3,9 \\
\hline B. plantaginea & 1 & 0,5 & 1 & 0,4 & 1 & 0,2 & 3 & 1,1 & 16 & 4,5 \\
\hline R. raphanistrum & 38 & 21,2 & 24 & 9,3 & 34 & 7,8 & 14 & 5,4 & 4 & 1,1 \\
\hline Outras* & 65 & 36,3 & 39 & 15,1 & 73 & 16,7 & 54 & 20,8 & 49 & 13,8 \\
\hline Total & 179 & 100 & 258 & 100 & 436 & 100 & 259 & 100 & 354 & 100 \\
\hline
\end{tabular}

* Eleusine indica, Bidens pilosa, Sonchus oleraceus, Stachys arvensis, Echinochloa colonum, Physalis angulata, Portulaca oleracea, Emilia sonchifolia, Euphorbia heterophylla, Galinsoga parviflora, Solanum americanum e Coronopus didymus.

Tabela 3 - Biomassa seca de plantas daninhas, em gramas por $\mathrm{m}^{2}$ (BS) e porcentagem de biomassa de cada espécie em relação à biomassa seca total, observada para os diferentes períodos de convivência no sistema de plantio direto

\begin{tabular}{|c|c|c|c|c|c|c|c|c|c|c|c|c|}
\hline \multirow{3}{*}{ Espécie } & \multicolumn{12}{|c|}{ Período de avaliação / Dia após a emergência } \\
\hline & \multicolumn{2}{|c|}{15} & \multicolumn{2}{|c|}{30} & \multicolumn{2}{|c|}{45} & \multicolumn{2}{|c|}{60} & \multicolumn{2}{|c|}{75} & \multicolumn{2}{|c|}{200} \\
\hline & $\mathrm{BS}$ & $\%$ & $\mathrm{BS}$ & $\%$ & $\mathrm{BS}$ & $\%$ & $\mathrm{BS}$ & $\%$ & $\mathrm{BS}$ & $\%$ & $\mathrm{BS}$ & $\%$ \\
\hline C. rotundus & 4,97 & 52,5 & 50,4 & 57,3 & 95,2 & 43,6 & 89,8 & 38,4 & 55,5 & 16,8 & 3,12 & 0,6 \\
\hline A. conyzoides & 0,25 & 2,6 & 4,5 & 5,2 & 17,3 & 7,9 & 24,7 & 10,6 & 57,1 & 18,6 & 129,6 & 26,6 \\
\hline D. horizontalis & 0,12 & 1,3 & 0,7 & 0,76 & 13,4 & 6,1 & 7,0 & 3,0 & 70,2 & 22,8 & 134,5 & 27,6 \\
\hline B. plantaginea & 0,03 & 0,3 & 0,6 & 0,70 & 0,9 & 0,4 & 12,1 & 5,2 & 35,5 & 11,5 & 83,56 & 17,15 \\
\hline R. raphanistrum & 2,85 & 30,1 & 20,0 & 22,7 & 54,6 & 25 & 31,2 & 13,4 & 6,26 & 2,0 & 0,0 & 0,0 \\
\hline Outras* & 1,26 & 13,3 & 11,7 & 13,3 & 36,7 & 17,3 & 68,8 & 29,1 & 86,7 & 28,2 & 136,4 & 28,8 \\
\hline Total & 9,47 & 100 & 87,9 & 100 & 218,1 & 100 & 233,6 & 100 & 307,3 & 100 & 487,2 & 100 \\
\hline
\end{tabular}

* Eleusine indica, Bidens pilosa, Sonchus oleraceus, Stachys arvensis, Echinochloa colonum, Physalis angulata, Portulaca oleracea, Emilia sonchifolia, Euphorbia heterophylla, Galinsoga parviflora, Solanum americanum e Coronopus didymus. 


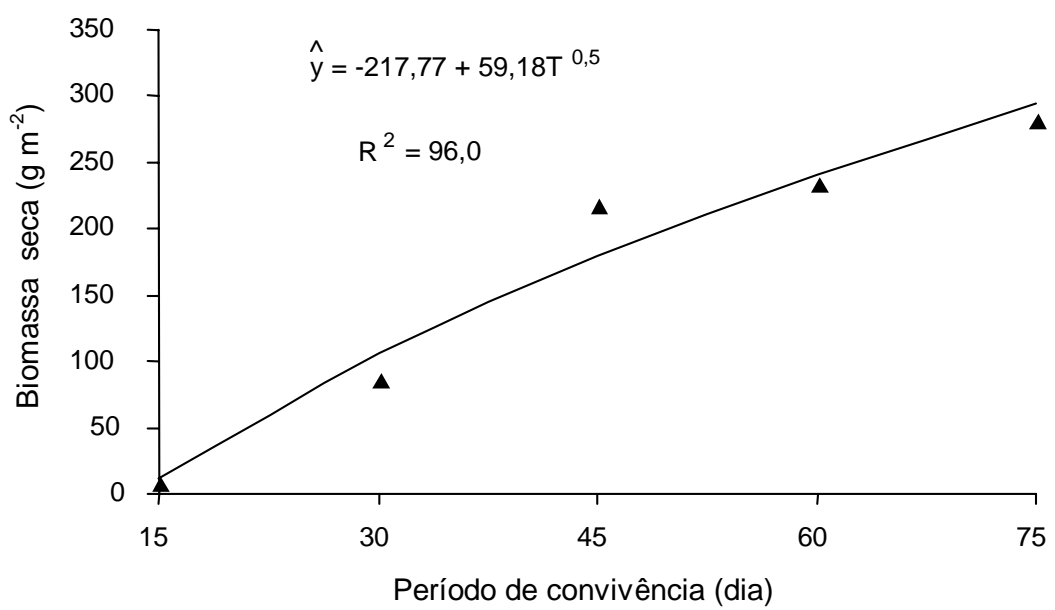

Figura 1 - Biomassa seca do total de plantas daninhas em função dos períodos de convivência destas com a cultura do algodão em sistema de plantio direto.

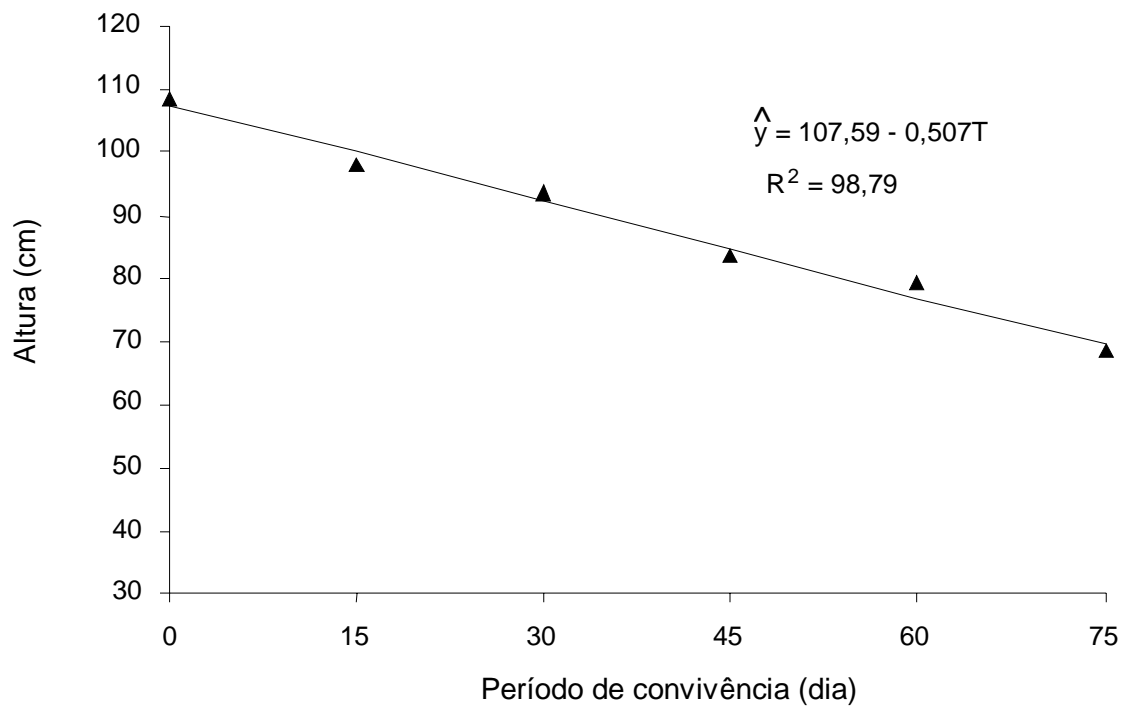

Figura 2 - Altura de plantas de algodão aos 125 DAE em função dos períodos de convivência destas com plantas daninhas em sistema de plantio direto.

Quando se mantiveram as plantas daninhas se desenvolvendo junto com o algodoeiro por períodos de 15, 30, 45 e 60 dias e também no tratamento mantido livre de plantas daninhas durante todo o ciclo, a altura do algodoeiro diferiu daquela da testemunha sem capina (Tabela 4). A altura média do algodoeiro submetido a 60 e 75 dias de convivência com as plantas daninhas não diferiu daquela das plantas de algodão que conviveram com as plantas daninhas por todo o ciclo, mostrando que o máximo efeito das plantas daninhas na altura das plantas de algodão se manifesta em período menor que 75 dias de convivência.
Houve redução de aproximadamente 37\% na altura média das plantas de algodoeiro quando se comparou o tratamento sempre "no limpo" com o que permaneceu com as plantas daninhas durante todo o ciclo da cultura. Guerra Filho (1980) observou em sistema de plantio convencional que, quando a cultura do algodão conviveu com as plantas daninhas durante 40 , 60 e 80 dias e por todo o ciclo, as reduções na altura de plantas do algodão foram de 21,36 , 44 e 48\%, respectivamente. Resultados semelhantes foram relatados por Buchanan \& Burns (1970), Laca-Buendia et al. (1974) e Rushing et al. (1985). 
Tabela 4 - Altura de planta, número de nós para inserção do primeiro ramo frutífero, número de maçãs por planta e produtividade de algodão em caroço nos diferentes períodos de convivência das plantas daninhas com o algodoeiro em sistema de plantio direto

\begin{tabular}{|c|c|c|c|c|}
\hline \multirow[b]{2}{*}{$\begin{array}{l}\text { Período de } \\
\text { convivência }\end{array}$} & \multicolumn{4}{|c|}{ Características } \\
\hline & $\begin{array}{l}\text { Altura } \\
(\mathrm{cm})\end{array}$ & $\begin{array}{l}\text { № de nós } \\
\text { (n⿳⺈/planta) }\end{array}$ & $\begin{array}{c}\mathrm{N}^{\mathrm{o}} \mathrm{de} \\
\text { maçãs } \\
\left(\mathrm{n}^{0} \mathrm{o} / \text { planta }\right)\end{array}$ & $\begin{array}{c}\text { Produti- } \\
\text { vidade } \\
\left(@ \mathrm{ha}^{-1}\right)\end{array}$ \\
\hline 0 & $108,70^{1 /}$ & $6,90^{1 /}$ & $14,25^{1 /}$ & $164,43^{1 /}$ \\
\hline 15 & $97,82^{\frac{1}{}}$ & $7,47^{1 /}$ & $12,62^{1 !}$ & $143,45^{1 /}$ \\
\hline 30 & $93,42^{\frac{1}{\prime}}$ & $7,32^{\frac{1}{\prime}}$ & $9,02^{1^{\prime \prime}}$ & $148,71^{1 /}$ \\
\hline 45 & $83,77^{1 /}$ & $8,12^{\frac{1}{}}$ & $6,55^{1 /}$ & $122,55^{1 /}$ \\
\hline 60 & 79,05 & $8,95^{1 /}$ & $3,97^{1 /}$ & $115,87^{1 /}$ \\
\hline 75 & 68,62 & $9,30^{1 /}$ & 1,75 & $72,07^{11}$ \\
\hline $\begin{array}{c}\text { Testemunha } \\
\text { sem capina }\end{array}$ & 68,02 & 10,70 & 1,45 & 30,93 \\
\hline $\mathrm{CV}(\%)$ & 11,21 & 8,40 & 22,38 & 17,05 \\
\hline
\end{tabular}

I/ Diferem estatisticamente da testemunha sem capina pelo teste de Dunnett, a 5\% de probabilidade.

A área foliar da planta de algodão segue comportamento semelhante ao da altura de planta (Souza \& Silva, 1992). O índice de área foliar aumenta lentamente nas primeiras seis a sete semanas; a partir daí, aumenta rapidamente até os 75 dias, quando torna a crescer lentamente (Oosterhuis, 1999). Em contraste com esse período inicial de crescimento lento do algodão, as plantas daninhas presentes na área em alta densidade (Tabela 2) apresentaram alta taxa de crescimento (Figura 1), provocando, entre outras situações de interferência, o sombreamento das plantas de algodão e reduzindo a sua altura média. $O$ fato de o algodoeiro ser do metabolismo $\mathrm{C}_{3}$ (Benedict, 1984), com elevada taxa de fotorrespiração (Hesketh, 1967), alto ponto de compensação de $\mathrm{CO}_{2} \mathrm{e}$ baixa taxa de fotossíntese líquida em condições de alta luminosidade (El-Sharkawy et al., 1965), faz dele uma cultura muito sensível à interferência de plantas daninhas. Muramoto et al. (1967), estudando taxas de fotossintese líquida de folhas de algodoeiro herbáceo précondicionadas por vários regimes de luz, verificaram que o sombreamento causa reduções importantes na fotossintese das folhas individualmente.

O número médio de nós para inserção do primeiro ramo frutífero nas plantas de algodão foi igual a sete no tratamento em que estas foram mantidas livres das plantas daninhas, incluindo o nó cotiledonar (Tabela 4). Roselem (2000) relata que o primeiro ramo frutífero deve aparecer no sexto ou sétimo nó, incluindo o nó cotiledonar. À medida que aumentaram os períodos de convivência de plantas daninhas (Figura 3), ocorreu aumento no número médio de nós para o aparecimento do primeiro ramo frutífero.

$\mathrm{O}$ número médio de nós para o aparecimento do primeiro ramo frutífero nos períodos de convivência de 15, 30 e 45 dias e no tratamento livre das plantas daninhas foi menor do que o observado na testemunha sem capina. A partir de 60 dias de convivência já não houve diferença, quando comparado com a testemunha sem capina (Tabela 4).

A altura de inserção do primeiro ramo frutífero, em relação ao número de nós, difere nas espécies, raças e cultivares de algodoeiro, mas pode ser modificada pelas condições ambientais (Souza \& Beltrão, 1999). O aumento do período de interferência possivelmente ocasionou a limitação do uso de água, luz, $\mathrm{CO}_{2}$, entre outros, o que causou o aumento do número médio de nós para aparecimento do primeiro ramo frutífero.

O número médio de maçãs reduziu com o aumento do período de convivência de plantas daninhas (Figura 3). Nos tratamentos sem convivência durante todo o ciclo e convivência cultura-planta daninha por 15, 30, 45 e 60 dias, o número médio de maçãs por planta foi maior que no tratamento em que as plantas daninhas e o algodão conviveram por 75 dias (Tabela 4). Roselem (2000) afirma que a queda das estruturas reprodutivas é regulada pelo balanço entre açúcares no tecido e o teor de etileno. Portanto, qualquer fator que determine queda na fotossíntese (auto-sombreamento por crescimento excessivo, muitos dias nublados e temperaturas altas e outros) ou aumento no gasto metabólico resultará em queda das estruturas reprodutivas. Assim, a redução no número médio de maçãs com o aumento do período de convivência cultura-planta daninha se deveu possivelmente à interferência das plantas daninhas, que afetou negativamente as características do algodoeiro avaliadas e, como conseqüência, provocou redução de emissão de estruturas reprodutivas e também queda acentuada das estruturas reprodutivas emitidas. 
Guerra Filho (1980) observou redução do número de capulhos e atribuiu esse efeito principalmente à interferência das plantas daninhas, que reduziram o potencial de produção da planta de algodão por meio da diminuição do seu porte e, também, do índice de vingamento.

No tratamento em que cultura e plantas daninhas conviveram 75 dias, observou-se redução no número médio de maçãs de aproximadamente $88 \%$, enquanto para o mesmo período de convivência a redução no rendimento de algodão em caroço foi de $44 \%$. Essa recuperação do potencial produtivo do algodoeiro possivelmente seja explicada pela ausência das plantas daninhas a partir desse período $(75$ dias após a emergência) até a colheita, permitindo assim o desenvolvimento de novas estruturas reprodutivas que resultaram em produção. Segundo Souza \& Beltrão (1999), o desenvolvimento de novas estruturas reprodutivas no algodão ocorre devido principalmente ao fato de o algodão apresentar, em cada nó onde se desenvolve uma folha frutífera, uma estrutura de reprodução com até três gemas: a principal, denominada axilar; a outra, extra-axilar; e uma terceira, mais rara, denominada acessória. Por um motivo qualquer, como por exemplo ataque de pragas, uma estrutura de reprodução pode cair e a outra gema, que estava dormente (hipnoplasto), ser induzida a brotar e originar outra flor. Essa particularidade do crescimento e do desenvolvimento é importante para a sobrevivência da planta e da espécie, pois ocorre a possibilidade de recuperação da produção.

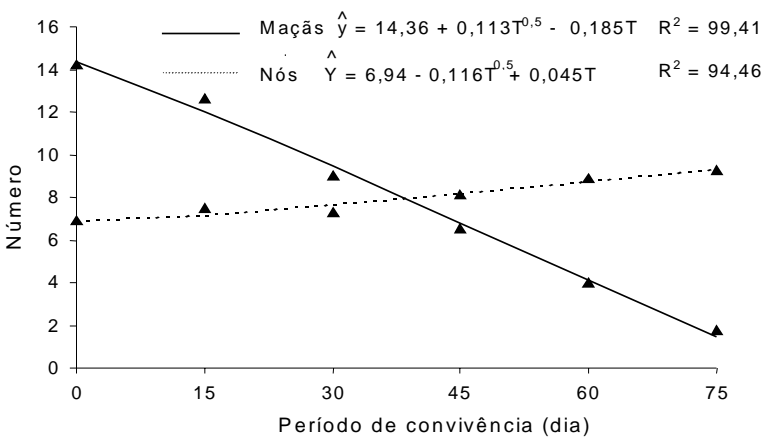

Figura 3 - Número médio de maçãs e número de nós até a inserção do primeiro ramo frutífero em função dos diferentes períodos de convivência das plantas daninhas com o algodoeiro em sistema de plantio direto.
A produtividade média de algodão em caroço no tratamento sem convivência com as plantas daninhas foi de 164,43 @ ha-1 (Figura 4).

Os tratamentos sem convivência durante todo o ciclo e 15, 30, 45, 60 e 75 dias com convivência e depois mantido "no limpo" até a colheita diferiram da testemunha sem capina (Tabela 4). Observou-se redução de $81,2 \%$ no rendimento do algodão em caroço quando se compararam as testemunhas com e sem convivência, em decorrência da interferência das plantas daninhas, competindo com o algodoeiro por água, luz, nutrientes e espaço. Em área ao lado deste experimento e nas mesmas condições de clima e tratos culturais em sistema de plantio convencional, foi verificada por Freitas et al. (2001), na safra de 1998/1999, redução de $94,5 \%$ da produtividade de algodão em caroço. Na Figura 4, também se observa que a interferência das plantas daninhas acontece nas primeiras semanas de desenvolvimento da cultura, o que irá provocar redução do rendimento. Em sistema de plantio convencional, Azevêdo (1992), Cia et al. (1978) e Guerra Filho (1980) verificaram que a competição com as plantas daninhas iniciou-se aproximadamente 20 dias após a emergência do algodão.

Considerando como aceitável a redução de produtividade de algodão em caroço de $5 \%$ em relação à produtividade máxima (Figura 4), estimou-se em 14 dias após a emergência da cultura o período em que as plantas daninhas e a cultura do algodoeiro podem conviver sem prejuízos. A partir desse período, as plantas daninhas devem ser controladas.

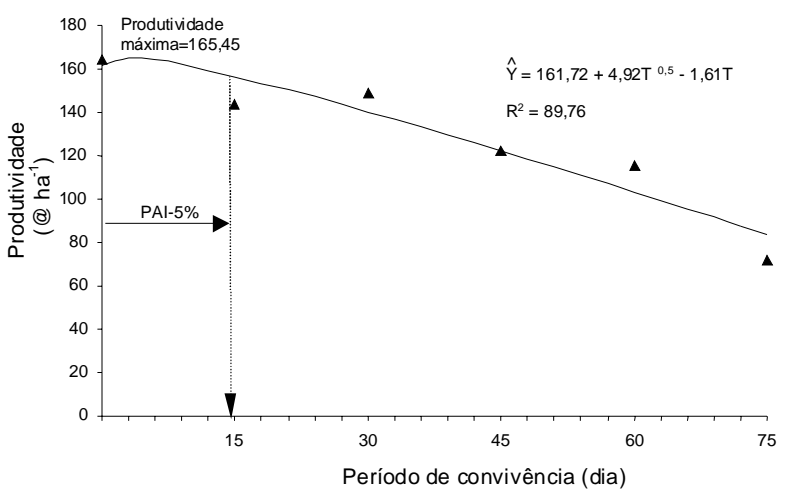

Figura 4 - Representação do período anterior à interferência (PAI), estimando-se redução de 5\% na produtividade de algodão em caroço em plantio direto.

Planta Daninha, Viçosa-MG, v.20, n.2, p.197-205, 2002 


\section{LITERATURA CITADA}

ALMEIDA, F. S. Influência da cobertura morta do plantio direto na biologia do solo. In: FUNDAÇÃO CARGIL. Atualização em plantio direto. Campinas: 1985. p. 103141.

AZEVÊDO, D. M. P.; BELTRÃO, N. E. M.; VIEIRA, D. J. N.; BALDOÍNO, L. Manejo de plantas daninhas no cultivo do algodoeiro herbáceo: Campina Grande: 1992. 11 p. (Comunicado técnico, 35).

BEltrão, N. E. M.; AZEVÊDO, D. M. P. Controle de plantas daninhas na cultura do algodoeiro. Campina Grande: EMBRAPA-CNPA/SP, 1994. 151 p.

BELTRÃO, N. E. M.; AZÊVEDO, D. M. P.; LIMA, R. N. Competição entre plantas daninhas e o algodoeiro herbáceo (Gossypim hirsutum raça latifolium L.) nos Estados da Paraíba e Pernambuco. Campina Grande: EMBRAPA-CNPA, 1979. p. 5-23. (EMBRAPA-CNPA. Boletim Técnico, 2).

BENEDICT, C. R. Physiology. In: KOHEL, R. J.; LEWIS, C. F. Cotton. Madison: American Society of Agronomy, 1984. p. 151-201. (Series Agronomy, 24).

BLANCO H. G.; OLIVEIRA, D. A. Contribuição para determinação do período de competição das plantas daninhas na cultura do algodão (Gossypium hirsutum L.). $\mathbf{O}$ Biológico, v. 42, p. 201-205, 1976.

BLANCO, H. G. A importância dos estudos ecológicos nos programas de controle de plantas daninhas. O Biológico, v. 38, n. 10 , p. $343-350,1972$.

BUCHANAN, G. A.; BURNS, E. R. Influence of weed competition on cotton. Weed Sci., v. 18, p. 149-154, 1970.

CIA, E. et al. Competição de plantas daninhas com a cultura do algodoeiro. R. Cient. Inst. Agron. Est. São Paulo, v. 37, p. 54-62, 1978.

COUSENS, R. Misinterpretation of results in weed research through inappropiate use of statistics. Weed Res., v. 28, n. 4 , p. $281-289,1988$.

EL-SHARKAWY, M.; HESKETH, J.; MURAMOTO, H. Leaf photosynthetic rates and other growth characteristics of leaf anatomy and $\mathrm{CO}_{2}$ diffusion resistence. Crop Sci., v. 5, p. $517-521,1965$.

FREITAS, R. S. Interferência de plantas daninhas na cultura do algodão (Gossypium hirsutum L. r. latifolium) nos sistemas de plantio direto e convencional. Viçosa, MG: Universidade Federal de Viçosa, 2001. 50 p. Dissertação (Mestrado em Fitotecnia) - Universidade Federal de Viçosa, 2001.
GUERRA FILHO, T. Comportamento do algodoeiro (Gossypium hisutum L.), em diferentes densidades de plantio, sob períodos de competição com plantas daninhas. Viçosa, MG: Universidade Federal de Viçosa, 1980. 81 p. Dissertação (Mestrado em Fitotecnia) Universidade Federal de Viçosa, 1980.

HESKETH, J. Enhancement of photosynthetic $\mathrm{CO}_{2}$ assimilation in the abrance of oxygen as dependent upon species and temperature. Planta, v. 76, p. 371-374, 1967.

LACA-BUENDIA, J. P. et al. Épocas críticas de competição das plantas daninhas com a cultura algodoeira (Gossypium hirsutum L.) no Estado de Minas Gerais. Planta Daninha, v. 2, n. 2, p. 89-95, 1979.

LACA-BUENDIA, J. P. et al. Épocas críticas de competição das plantas daninhas com a cultura algodoeira (Gossypium hirsutum L.) no Norte de Minas Gerais. In: EPAMIG. Projeto Algodão. Belo Horinzonte, 1974. p. 206-19. (Relatório anual).

MELO, H. B. et al. Interferência das plantas daninhas na cultura da soja cultivada em dois solos espaçamentos entre linhas. Planta Daninha, v. 19, n. 2, p. 187-191, 2001.

MURAMOTO, H.; HESKETH, J. D.; ELMORE, C. D. Leaf growth, leaf aging and leaf photosynthetic rates of cotton plants. In: BELTWIDE COTTON PRODUCTION RESEARCH CONFERENCES, 1967, Dallas.

Proceedings... Memphis: National Cotton Council, 1967. p. 161-165.

OOSTERHUIS, D. M. Growth and development of a cotton plant. In: CIA, E.; FREIRE, E.C; SANTOS, W.J.S. Cultura do algodoeiro. Piracicaba: POTAFOS, 1999. p. 101-120.

PITELLI, R. A. Interferência de plantas daninhas em culturas agrícolas. Informe Agropecuário, v. 11, n. 129, p. 16-27, 1985.

RIGHI, N. R.; FERRAZ, C. A. M.; CORRÊA, D. M. Cultura. In: NEVES, O. S. et al. Cultura e adubação do algodoeiro. São Paulo: Instituto Brasileiro de Potassa, 1965. p. 255-317.

ROSELEM, C. A. Ecofisiologia e manejo da cultura do algodoeiro. In: CONGRESSO INTERNACIONAL DO AGRONEGÓCIO DO ALGODÃO, SEMINÁRIO ESTADUAL DA CULTURA DO ALGODÃO 5., 2000, Cuiabá. Anais... Cuiabá: Fundação MT, 2000. p. 203-212.

RUSHING, D. W.; MURRAY, D. S.; VERHALEN, L. M. Weed interference with cotton (Gossypium hirsutum). I. Buffalobur (Solanum rostratum). Weed Sci., v. 33, p. 810814, 1985. 
SCHULTZ, L. A. Manual do plantio direto: técnicas e perspectivas. 2.ed. Porto Alegre: SAGRA, 1987. 124 p.

SOUZA, J. G.; SILVA, J. V. Relações entre fenologia, fotossíntese e respiração no algodoeiro selecionado quanto a alto teor de amido nas raízes. Pesq. Agropec. Bras., v. 29, n. 5, p. 743-749, 1992.
SOUZA, J. G.; BELTRÃO, N. E. M. Fisiologia. In: O AGRONEGÓCIO do algodão no Brasil. Brasília, DF: EMBRAPA, 1999. p. 87-116.

VIDAL, R. A. et al. Palha no sistema de semeadura direta reduz a infestação de gramíneas anuais e aumenta a produtividade da soja. Ciência Rural, v. 28, n. 3, p. 373-377, 1998. 